\title{
LA LICENCIA AMBIENTAL: ¿INSTRUMENTO DE COMANDO Y CONTROL POR EXCEPCIÓN?*
}

\author{
ENVIRONMENTAL LICENSING: AN \\ INSTRUMENT OF COMMAND AND \\ CONTROL BY EXCEPTION?
}

\author{
Juliette Sleman-Chams** \\ Carlos Javier Velásquez-Muñoz **** \\ Fecha de recepción: $x x$ de $x x x x x$ de $201 x$ \\ Fecha de aceptación: $x x$ de $x x x x$ de $201 x$ \\ Disponible en linea: 31 de mayo de 2016
}

\section{Para citar este artículo/To cite this article}

\begin{abstract}
Sleman-Chams, Juliette \& Velásquez-Muñoz, Carlos Javier, La licencia ambiental: ¿instrumento de comando y control por excepción?, 132 Vniversitas, 483-514 (2016). http://dx.doi.org/10.11144/Javeriana.vj132.laic

doi:10.11144/Javeriana.vj132.laic
\end{abstract}

* Este artículo es resultado de la investigación que lleva el mismo nombre y que fue realizada en la maestría en derecho de la Universidad del Norte, Barranquilla, Colombia, línea de investigación en derecho ambiental y urbano-territorial del Grupo de Investigación en Derecho y Ciencia Política, GIDECP, de la misma Universidad.

** Magíster en derecho, Universidad del Norte, Barranquilla, Colombia. Especialista en derecho ambiental, Universidad Externado de Colombia. Abogada, Universidad del Norte. Coordinadora, subdirección de Gestión Ambiental de la Corporación Autónoma Regional del Atlántico, CRA, autoridad ambiental del Departamento del Atlántico, Colombia. Contacto: jsleman@crautonoma.gov.co, juliettesleman@hotmail.com

*** Doctor en derecho, Universidad de Salamanca, España. Magíster en Derecho Ambiental, Universidad del País Vasco, España. Especialista y posgraduado en derecho ambiental y administrativo. Director del Centro de Estudios Urbano-Regionales de la Universidad del Norte, URBANUM. Director de la maestría y la especialización en derecho ambiental y urbano-territorial, Universidad del Norte. Contacto: cvelasquez@uninorte.edu.co 


\section{RESUMEN}

Este artículo analiza la realidad del principal instrumento de comando y control existente en la legislación ambiental colombiana: la licencia ambiental. Desde su primera reglamentación, por cuenta del Decreto 1753 de 1994, ha recibido varias modificaciones que al parecer, a pesar de su importancia, la han convertido en instrumento de utilización excepcional. El artículo profundiza en el alcance de cada una de las modificaciones realizadas, y las justificaciones dadas por el gobierno de turno para establecer si estuvieron fundadas en estrictos avances frente al control de los impactos ambientales o si, por el contrario, hay otros motivos e intereses ajenos a los estrictamente ambientales.

Palabras clave: Licencia ambiental; protección ambiental; derecho ambiental; Colombia; comando y control. 


\section{ABSTRACT}

This article analyzes the situation of the most important instrument of command and control existing in the Colombian environmental legislation: the environmental license. Since its first formal regulation, on behalf of Decree 1753 of August 3, 1994, has received several modifications which, apparently, have made, in spite of its importance, in an instrument of command and control by exception. The article revises on the scope of each of the modifications and the justifications put forward by the government of the day, to establish if indeed they were founded on strict gains against the control of environmental impacts from projects, works or activities, or if, on the contrary, the changes correspond to other outside interests to strict environmental control.

Keywords: Environmental license; environmental protection; Environmental Law; Colombia; command and control.

\section{SUMARIO}

Introducción.- I. La licencia Ambiental: FinAlidad y AlCANCES.- $A$. Desarrollo legal.- B. Desarrollo reglamentario de la licencia ambiental en Colombia.- C. Contexto político y económico en las reformas reglamentarias de la licencia ambiental en Colombia.- Conclusiones.- BiBLIOGRAFíA. 


\section{INTRODUCCIÓN}

La obligación de evaluar los impactos ambientales constituye un principio esencial, no solo de la política ambiental mundial ${ }^{1}$, sino también de la política ambiental colombiana ${ }^{2}$.

A pesar de la redacción alcanzada en la ley marco, el mandato de evaluar impactos ambientales no es de reciente aparición. No está de más recalcar que Colombia ha sido, paradójicamente ${ }^{3}$, uno de los pioneros en expedición de normas de protección ambiental. La primera norma ambiental del país ${ }^{4}$ - Ley 23 de $1973^{5}$ - incorporó el principio, el cual, a su vez, fue resultado de los esfuerzos internacionales por garantizar un medio humano de calidad ${ }^{6}$. En ese sentido, la citada Ley dispuso:

1 Lo anterior se pone de presente en el principio 17 de la Declaración de la Cumbre de la Organización de las Naciones Unidas sobre el Medio Ambiente y el Desarrollo, mejor conocida como Declaración de Río de Janeiro, la cual señala: "Deberá emprenderse una evaluación del impacto ambiental, en calidad de instrumento nacional, respecto de cualquier actividad propuesta que probablemente haya de producir un impacto negativo considerable en el medio ambiente y que esté sujeta a la decisión de una autoridad nacional competente". Organización de las Naciones Unidas, ONU, Declaración de Río sobre el Medio Ambiente y el Desarrollo, Cumbre para la Tierra, Río de Janeiro, Brasil, 3-14 de junio de 1992, principio 17. Disponible en: http://www.un.org/spanish/esa/sustdev/documents/declaracionrio.htm, http://www.un.org/ spanish/esa/sustdev/agenda21/agenda21toc.htm

2 La ley marco ambiental (Ley 99 de 1993) señala desde su artículo 1, numeral 11: "Artículo 1.- Principios generales ambientales. La política ambiental colombiana seguirá los siguientes principios generales:... 11. Los estudios de impacto ambiental serán el instrumento básico para la toma de decisiones respecto a la construcción de obras y actividades que afecten significativamente el medio ambiente natural o artificial". Colombia, Ley 99 de 1993, Ley General Ambiental de Colombia, por la cual se crea el Ministerio del Medio Ambiente, se reordena el sector público encargado de la gestión y conservación del medio ambiente y los recursos naturales renovables, se organiza el Sistema Nacional Ambiental, SINA, y se dictan otras disposiciones, 41.146 Diario Oficial, 22 de diciembre de 1993, artículo 1.11. Disponible en: http://www.secretariasenado.gov.co/senado/basedoc/ley_0099_1993.html

3 Colombia sigue siendo un paraíso para la inflación normativa en materia ambiental. Tanto ayer, como hoy, es profusa la implementación de normas ambientales; no obstante, es necesario alertar sobre la calidad, más que sobre la cantidad, ya que cuando estas se comparan con los estándares internacionales, las nuestras quedan relegadas por ser de bajísima factura técnica.

4 Siguiendo la nomenclatura de RAÚL BRAÑES (1997), para quien las normas ambientales pueden clasificarse de tres formas: a. normas generales con contenido ambiental; b. normas sectoriales de incidencia ambiental y c. normas ambientales propiamente dichas. Estas últimas, las que tienen como objetivo principal la defensa preventiva del medio ambiente y el uso racional de los recursos naturales. RAÚl BRAÑES, Manual de derecho ambiental mexicano (Fundación Mexicana para la Educación Ambiental, Fondo de Cultura Económica, FCE, México, 1997).

5 Colombia, Ley 23 de 1973, por la cual se conceden facultades extraordinarias al Presidente de la República para expedir el Código de Recursos Naturales y protección al medio ambiente y se dictan otras disposiciones, 19 de diciembre de 1973. Disponible en: http://www.alcaldia bogota.gov.co/sisjur/normas/Norma1.jsp?i=9018

6 La ley 23 de 1973 - y el consecuente Decreto Ley 2811 de 1974 — fue el resultado de la participación del presidente de la época, Misael Pastrana Borrero (1970-1974), en la Cumbre de 
Artículo 12. El gobierno nacional creará los sistemas técnicos de evaluación que le permitan hacer participar a los usuarios de los recursos ambientales en los gastos de protección y renovación de estos, cuando sean usados en beneficio de actividades lucrativas.

Artículo 13. Cuando técnicamente se establezca que han sobrepasado los niveles mínimos de contaminación o aprovechamiento o que hay una nueva contaminación no revista de manera especial, el gobierno nacional podrá inspeccionar los procesos industriales, comerciales o de cualquier otra índole, en orden a reducir o eliminar la contaminación y controlar la fuente de la misma...

Sin embargo, se atribuye al Código Nacional de los Recursos Naturales Renovables y de Protección del Medio Ambiente, CNRN (Decreto Ley 2811 de 1974) 7 , expedido en diciembre de 1974, haber acogido de forma explícita, no solo la obligación de evaluar los impactos ambientales, sino también el deber de obtener licencia como resultado de la evaluación. El artículo 28 de este estatuto señala:

Para la ejecución de obras, el establecimiento de industrias o el desarrollo de cualquiera otra actividad que, por sus características, pueda producir deterioro grave a los recursos naturales renovables o al ambiente o introducir modificaciones considerables o notorias al paisaje, será necesario el estudio ecológico y ambiental previo, y además, obtener licencia (negrillas fuera del original).

\footnotetext{
la Organización de las Naciones Unidas para el Medio Humano, celebrada en Estocolmo, Suecia, en la primavera de 1972. Esta cumbre produjo varios resultados, entre ellos, una importante Declaración de 26 Principios en los cuales se sientan las bases para la comprensión del desarrollo como un asunto humano más que económico y en los cuales el medio humano debe considerar el medio natural como parte inescindible de su existencia. Así se lee desde la proclama 1 de la Declaración: "El hombre es a la vez obra y artífice del medio que lo rodea, el cual le da sustento material y le brinda la oportunidad de desarrollarse intelectual, moral, social y espiritualmente. En la larga y tortuosa evolución de la raza humana en este planeta se ha llegado a una etapa en que, gracias a la rápida aceleración de la ciencia y la tecnología, el hombre ha adquirido el poder de transformar, de innumerables maneras y en una escala sin precedentes, cuanto lo rodea. Los dos aspectos del medio humano, el natural y el artificial, son esenciales para el bienestar del hombre y para el goce de los derechos humanos fundamentales, incluso el derecho a la vida misma" (negrillas fuera del original). Organización de las Naciones Unidas, ONU, Declaración de la Conferencia de las Naciones Unidas sobre el Medio Humano, Estocolmo, Suecia, 5-16 de junio de 1972. Disponible en: http://www.unep.org/documents. multilingual/default.asp?documentid=97\&articleid $=1503$

7 Colombia, Decreto Ley 2811 de 1974, por el cual se dicta el Código Nacional de Recursos Naturales Renovables y de Protección al Medio Ambiente, 34.243 Diario Oficial, 18 de diciembre de 1974. Disponible en: http://www.alcaldiabogota.gov.co/sisjur/normas/Norma1.jsp?i=1551\#0
} 
Lastimosamente, a pesar de la incorporación explícita en el Código, esta disposición nunca fue reglamentada, por lo que no se exigió licencia a las industrias y/o actividades.

En virtud de lo anterior, la normativa operativa para este instrumento de comando y control se dio a partir de la reglamentación de los artículos 79 y 80 de la Constitución de 1991, los cuales crearon el derecho a gozar de un ambiente sano, por una parte, e incorporaron el mandato de planificar el manejo y aprovechamiento de los recursos naturales, para garantizar su desarrollo sostenible, su conservación, restauración o sustitución y, sobre todo, para prevenir y controlar los factores de deterioro ambiental, imponer las sanciones legales y exigir la reparación de los daños causados, por otra.

La reglamentación de esos dos artículos, así como de otros 40 más ubicados en la Constitución Ecológica ${ }^{8}$ de Colombia, se dio con la expedición de la Ley 99 de 1993. Esta ley dedicó un título

8 Desde su creación, la Corte Constitucional, guardián de la supremacía e integridad de la Constitución Política, ha venido reconociendo en sus sentencias que nuestra Constitución es una verdadera Constitución Ecológica. Así aparece de manera diáfana y certera en la Sentencia T-411-92, cuando señala, en apartes: "En este orden de ideas, de una lectura sistemática, axiológica y finalista surge el concepto de Constitución Ecológica, conformado por las siguientes 34 disposiciones: Preámbulo (vida), 2 (fines esenciales del Estado: proteger la vida), 8 (obligación de proteger las riquezas culturales y naturales de la Nación), 11 (inviolabilidad del derecho a la vida), 44 (derechos fundamentales de los niños), 49 (atención de la salud y del saneamiento ambiental), 58 (función ecológica de la propiedad), 66 (créditos agropecuarios por calamidad ambiental), 67 (la educación para la protección del ambiente), 78 (regulación de la producción y comercialización de bienes y servicios), 79 (derecho a un ambiente sano y participación en las decisiones ambientales), 80 (planificación del manejo y aprovechamiento de los recursos naturales), 81 (prohibición de armas químicas, biológicas y nucleares), 82 (deber de proteger los recursos culturales y naturales del país), 215 (emergencia por perturbación o amenaza del orden ecológico), 226 (internacionalización de las relaciones ecológicas, 268-7 (fiscalización de los recursos naturales y del ambiente), 277-4 (defensa del ambiente como función del Procurador), 282-5 (el Defensor del Pueblo y las acciones populares como mecanismo de protección del ambiente), 289 (programas de cooperación e integración en zonas fronterizas para la preservación del ambiente), 300-2 (Asambleas Departamentales y medio ambiente), 301 (gestión administrativa y fiscal de los departamentos atendiendo a recursos naturales y a circunstancias ecológicas), 310 (control de densidad en San Andrés y Providencia con el fin de preservar el ambiente y los recursos naturales), 313-9 (Concejos Municipales y patrimonio ecológico), 317 y 294 (contribución de valorización para conservación del ambiente y los recursos naturales), 330-5 (Concejos de los territorios indígenas y preservación de los recursos naturales), 331 (Corporación del Río Grande de la Magdalena y preservación del ambiente), 332 (dominio del Estado sobre el subsuelo y los recursos naturales no renovables), 333 (limitaciones a la libertad económica por razones del medio ambiente), 334 (intervención estatal para la preservación de los recursos naturales y de un ambiente sano), 339 (política ambiental en el plan nacional de desarrollo), 340 (representación de los sectores ecológicos en el Consejo Nacional de Planeación), 366 (solución de necesidades del saneamiento ambiental y de agua potable como finalidad del Estado)". Corte Constitucional, Sentencia T-411-92, 17 de junio de 1992, magistrado ponente Alejandro Martínez-Caballero. Disponible en: http:// www.corteconstitucional.gov.co/relatoria/1992/T-411-92.htm 
completo, el VIII (artículos 49 a 62), a la licencia ambiental, en el que se establecen uno a uno los aspectos formales y operativos del instrumento.

A su vez, la Ley 99 de $1993^{9}$ ha sido reglamentada en varias ocasiones en relación con la licencia. La primera de ellas se dio por medio del Decreto 1753 del 3 de agosto de 1994 y la más reciente con el Decreto 2041 de 15 de octubre de 2014, el cual hay necesariamente que concordar con el Decreto Único del Sector Ambiente y Desarrollo Sostenible (Decreto 1076 de 26 de mayo de 2015) ${ }^{10}$, promulgado por el gobierno de Juan Manuel Santos-Calderón para cumplir, entre otros asuntos, los compromisos de ingreso a la Organización para Cooperación y el Desarrollo Económicos, OCDE. Un verdadero desaguisado jurídico, portador de una errónea y bajísima técnica de redacción, general y jurídica ${ }^{11}$.

Ahora bien, entre la primera norma y la más reciente han sido promulgadas ocho modificaciones generales en un período más bien corto. Si comparamos la situación colombiana con normativas ambientales de peso y de las cuales nuestro modelo acoge algunas prescripciones, como la existente en la Unión Europea, tenemos que mientras en el país ha habido una modificación cada tres años (en 24), la Directiva Comunitaria europea sobre el tema, expedida en $1985^{12}$, solo ha tenido tres (en 30 años).

9 Colombia, Ley 99 de 1993, Ley General Ambiental de Colombia, por la cual se crea el Ministerio del Medio Ambiente, se reordena el sector público encargado de la gestión y conservación del medio ambiente y los recursos naturales renovables, se organiza el Sistema Nacional Ambiental, SINA, y se dictan otras disposiciones, 41.146 Diario Oficial, 22 de diciembre de 1993. Disponible en: http://www.secretariasenado.gov.co/senado/basedoc/ley_0099_1993.html

10 Colombia, Decreto 1076 de 2015, Decreto único del Sector Medio Ambiente y Desarrollo Sostenible, 49.523 Diario Oficial, 26 de mayo de 2015. Disponible en: http://www.alcaldiabogota. gov.co/sisjur/normas/Norma1.jsp?i=62511

11 De este Decreto se pueden relevar muchos aspectos negativos, pues - como muchos lo han llamado - es un verdadero Frankenstein jurídico. No solo su nomenclatura es atípica para la técnica normativa, llena de números y numerales, sino que además carece de coherencia interna en la ubicación de temas; no hay justificación de los temas incluidos y la incoherencia en remisión a normas por fuera del texto. Pero quizás lo más preocupante es el asunto relacionado con las derogaciones. El artículo 3.1.1. de este Decreto señala una Derogatoria integral, en virtud de la cual este regula de manera íntegra las materias contempladas en él. Por consiguiente, quedan derogadas todas las disposiciones de naturaleza reglamentaria que versan sobre las mismas materias. Sin embargo, el Decreto no regula todas las materias ambientales y por otro lado, las materias estaban mucho más desarrolladas en los decretos anteriores. Este compilatorio no compila todos los asuntos, sino algunos y aprovecha para, de un tajo, "liberarse" de la normativa ambiental que estaba vigente.

12 Se trata de la Directiva Comunitaria 85/337/CEE del Consejo, relativa a la evaluación de las repercusiones de determinados proyectos públicos y privados sobre el medio ambiente, la cual ha sido modificada por la Directiva 97/11/CE del Consejo de 3 de marzo de 1997; la Directiva 
Pero no solo eso. Expertos y conocedores de la materia han advertido, de forma reiterada y sistemática, que las modificaciones han deformado el instrumento hasta convertirlo en mecanismo inocuo; se habla de flexibilización, descontrol, pérdida de fuerza, en últimas, de una herramienta de control por excepción.

Las anteriores situaciones generaron la necesidad de plantear interrogantes varios al respecto: a) ¿A qué se deben los cambios? b) ¿Por qué tanta inestabilidad en el más importante (único) instrumento de comando y control ambiental? c) ¿Qué móviles han guiado las acciones de los gobiernos en cada modificación? d) ¿Son las modificaciones saltos de importancia en materia de protección ambiental? $\mathrm{O}$, por el contrario, ¿obedecen a motivaciones distintas a las de cuidado y conservación ambiental?

Con la intención de responder los interrogantes planteados, se redactó este artículo, que es resultado de la investigación que lleva su mismo nombre y que fue realizada durante la maestría en derecho de la Universidad del Norte (Barranquilla, Colombia).

Metodológicamente, la investigación puede encuadrarse en la tipología de investigaciones jurídicas sistematizantes o sistematizadoras $^{13}$, en la medida en que constituye un estudio pormenorizado sobre el marco normativo de la licencia ambiental en Colombia, para luego sistematizar la información y realizar un análisis descriptivo, crítico y de ser posible prescriptivo, sobre los aspectos planteados.

Para llegar a respuestas sobre los interrogantes planteados, se hizo un levantamiento de información jurídica secundaria y se estudió a partir de la elaboración de matrices de análisis por variables comparativas.

2001/42/CE del Parlamento Europeo y del Consejo, de 27 de junio de 2001, y la Directiva 2003/35/CE del Parlamento Europeo y del Consejo, de 26 de mayo de 2003, por la que se establecen medidas para la participación del público en la elaboración de determinados planes y programas relacionados con el medio ambiente. Unión Europea, Directiva Comunitaria 85/337/CEE del Consejo, 27 de junio de 1985, relativa a la evaluación de las repercusiones de determinados proyectos públicos y privados sobre el medio ambiente [modificaciones Directiva 97/11/CE, Directiva 2001/42/CE y Directiva 2003/35/CE]. Disponible en: http://eur-lex.europa. eu/legal-content/ES/TXT/?uri=URISERV\%3A128163

13 De acuerdo con Virgilio LATORRE, la investigación sistematizadora es predominantemente descriptiva, ya que entraña una tarea comprensiva de un fenómeno, en este caso normativo, pero además no es una mera descripción, sino que requiere dotar de sentido y contenido sistematizador, creando cuerpos doctrinales que permitan analizar e identificar instituciones y a su delimitación frente a otras instituciones. Virgilio Latorre, Bases metodológicas de la investigación jurídica, 119 (Tirant lo Blanch, Valencia, 2011). 


\section{LA LICENCIA AMBIENTAL: FINALIDAD Y ALCANCES}

\section{Desarrollo legal}

De acuerdo con Andrés BetAnCor-RodríGuez ${ }^{14}$, el control de la administración previo a la ejecución de actividades que tienen o pueden tener un singular impacto ambiental es el más importante instrumento de prevención ambiental. Su importancia es tal que ello explica encontrar varias herramientas de formalización jurídica de control; sin embargo, dentro de lo que se conoce como técnica autorizatoria de la policía administrativa, dos son las formas más relevantes, aunque una de ellas predomina sobre las demás: la licencia.

De conformidad con el artículo 49 de la Ley 99 de 1993, en Colombia la licencia ambiental es requisito obligatorio y previo para la ejecución de obras, el establecimiento de industrias y/o desarrollo de cualquier actividad, que pueda producir deterioro grave a los recursos naturales renovables o al medio ambiente o introducir modificaciones considerables o notorias al paisaje.

De entrada, la ley deja en claro que la obligación de obtener licencia solo opera para obras, industrias o actividades que pueden producir deterioros graves o introducir modificaciones considerables o notorias al paisaje; el resto, es decir, aquellas que no produ-

14 Andrés BetAnCor-RodríGuez, Instituciones de derecho ambiental (La Ley, Madrid, 2001). 
cen deterioro grave — sino de otro tipo (¿menores?, ¿leves?) — no requieren el instrumento ${ }^{15} 16$.

El artículo 50 de la Ley 99 de 1993 define la licencia ambiental como una autorización otorgada por la autoridad ambiental para ejecutar una obra o actividad, la cual está sujeta al cumplimiento por parte del beneficiario de los requisitos que la misma establece para prevenir, mitigar, corregir o compensar los efectos ambientales de la obra o actividad licenciada.

En relación con las competencias para su otorgamiento, el artículo 51 de la Ley 99 de 1993 establece que la que ejerce el Ministerio del Medio Ambiente ${ }^{17}$ es privativa y excluyente para los

15 Sin embargo, como se señala en el cuerpo de este artículo, varios han sido los intentos para juridificar las actividades de impactos no graves. En ese sentido, en marzo de 1997 se expidió el Decreto 883, por medio del cual se definió un instrumento administrativo para someter a control las actividades que no causan deterioro grave a los recursos naturales renovables o al medio ambiente, ni modificaciones notorias al paisaje y, por tanto, no requerían licencia ambiental; así como aquellos proyectos, obras o actividades que forman parte de otros, y que teniendo licencia o plan de manejo, recuperación o restauración ambiental, necesitaban ciertos ajustes o complementos. Colombia, Decreto 883 de 1997, por el cual se regulan de manera general algunas actividades y se define un instrumento administrativo para la prevención o el control de los factores de deterioro ambiental, 43.013 Diario Oficial, 4 de abril de 1997. Disponible en: http://www.icbf.gov.co/cargues/avance/docs/decreto_0883_1997.htm. Este Decreto fue bien recibido por la comunidad académica y las organizaciones ambientales; sin embargo, sucumbió ante las presiones gremiales y fue declarado nulo por el Consejo de Estado. Consejo de Estado, Sección Primera, Expediente 4500, Sentencia del 26 de febrero de 1998, magistrado ponente Ernesto Rafael-Ariza. Disponible en: http://190.24.134.114:8080/ WebRelatoria/ce/index.xhtml

Más adelante, se intentó retomar el asunto y para ello, se introdujo en un decreto de reducción de trámites, el 266 de febrero de 2000, disposiciones para reglamentar los instrumentos de comando y control para actividades antrópicas que generasen impactos ambientales no considerados como graves. El parágrafo 2 del artículo 50 de este decreto estableció: "El Ministerio del Medio Ambiente podrá definir mecanismos e instrumentos administrativos de prevención, control y seguimiento ambiental para la ejecución de proyectos, obras o actividades que no generen impactos significativos al medio ambiente, los recursos naturales renovables o al paisaje". Colombia, Decreto 266 de 2000, por el cual se dictan normas para suprimir y reformar las regulaciones, trámites y procedimientos, 43.906 Diario Oficial, 22 de febrero de 2000. Disponible en: http://www.alcaldiabogota.gov.co/sisjur/normas/Normal.jsp?i=3281. Sin embargo, este decreto corrió igual suerte que el anterior, pero en este caso fue declarado inexequible por la Corte Constitucional. Corte Constitucional, Sentencia C-1316-00, 26 de septiembre de 2000, magistrado ponente Carlos Gaviria-Díaz. Disponible en: http://www. corteconstitucional.gov.co/relatoria/2000/C-1316-00.htm

16 Lo anterior no quiere decir que si una actividad que puede producir impactos ambientales, no está en las listas reglamentarias como obligada a tramitar licencia, por esa circunstancia se exime del control ambiental. Nada más alejado del deber; recordemos que el artículo 80 de la Constitución Política señala que le corresponde al Estado prevenir la degradación del ambiente y, en ese sentido, el beneficiario de la obra, proyecto o actividad debe tramitar ante la respectiva autoridad ambiental competente las autorizaciones, permisos y concesiones sectoriales por cada uno de los medios receptores y/o recursos naturales afectados.

17 Hoy, de acuerdo con la actual nomenclatura de la Rama Ejecutiva del Poder Público establecida en la Ley 1444 de 2011, Ministerio de Ambiente y Desarrollo Sostenible. No está de más recor- 
casos de deterioro más graves, determinados de forma taxativa por la preceptiva reglamentación ${ }^{18}$. Por su parte, remite a los reglamentos la asignación de asuntos del conocimiento de las autoridades ambientales regionales; las que para la expedición de la Ley 99 eran las Corporaciones Autónomas Regionales, CAR (artículo 23) y las autoridades ambientales de los grandes centros urbanos (artículos 55 y 66$)^{19}$.

Por su parte, el artículo 52 de la Ley 99 de 1993 estableció un elenco de 13 proyectos, industrias o actividades que debían contar para su desarrollo con la respectiva licencia otorgada por el Ministerio ${ }^{20}$, lista que ha venido variando.

dar que el rector del sector ambiental en Colombia ha cambiado tres veces de denominación: en principio, la Ley 99 de 1993 creó el Ministerio del Medio Ambiente; con posterioridad, el primer gobierno de Álvaro Uribe-Vélez — por medio del Decreto 216 de 2003-cambió la estructura de la Rama Ejecutiva del poder público y fusionó el ministerio de Desarrollo con el de Ambiente para crear el Ministerio de Ambiente, Vivienda y Desarrollo Territorial. Por último, como ya se anotó, el primer gobierno de Juan Manuel Santos reorganizó el sector central de la administración pública nacional y ordenó la nomenclatura actual.

18 Hoy, esta función asignada por la Ley 99 de 1993 al Ministerio, como consecuencia de la expedición de la Ley 1444 de 2011 y el Decreto 3573 de 2011, ha pasado a la Autoridad Nacional de Licencias Ambientales, ANLA. De acuerdo con el artículo 2 del citado Decreto, la Autoridad Nacional de Licencias Ambientales - ANLA - es la encargada de que los proyectos, obras o actividades sujetos de licenciamiento, permiso o trámite ambiental cumplan con la normativa ambiental, de tal manera que contribuyan al desarrollo sostenible ambiental del país.

19 A esto se agregan las competencias ambientales de los Establecimientos Públicos Ambientales creados por medio de la Ley 768 de 2002 y las de los Distritos, Ley 1617 de octubre de 2013. Colombia, Ley 768 de 2002, por la cual se adopta el régimen político, administrativo y fiscal de los distritos portuario e industrial de Barranquilla, Turístico y Cultural de Cartagena de Indias y Turístico, Cultural e Histórico de Santa Marta, 44.893 Diario Oficial, 7 de agosto de 2002. Disponible en: http://www.secretariasenado.gov.co/senado/basedoc/ley_0768_2002. html. Colombia, Ley 1617 de 2013, por la cual se expide el Régimen para los Distritos Especiales, 48.695 Diario Oficial, 5 de febrero de 2013. Disponible en: http://www.secretariasenado. gov.co/senado/basedoc/ley_1617_2013.html

20 De acuerdo con el artículo 52 de la Ley 99 de 1993, estas obras, proyectos o actividades eran: 1. Ejecución de obras y actividades de exploración, explotación, transporte, conducción y depósito de hidrocarburos, y construcción de refinerías. 2. Ejecución de proyectos de gran minería. 3. Construcción de presas, represas, o embalses con capacidad superior a doscientos millones de metros cúbicos, y construcción de centrales generadoras de energía eléctrica que excedan de $100.000 \mathrm{~kW}$ de capacidad instalada así como el tendido de las líneas de transmisión del sistema nacional de interconexión eléctrica y proyectos de exploración y uso de fuentes de energía virtualmente contaminantes. 4. Construcción o ampliación de puertos marítimos de gran calado. 5. Construcción de aeropuertos internacionales. 6. Ejecución de obras públicas de las redes vial, fluvial y ferroviaria nacionales. 7. Construcción de distritos de riego para más de 20.000 hectáreas. 8. Producción e importación de pesticidas, y de aquellas sustancias, materiales o productos sujetos a controles por virtud de tratados, convenios y protocolos internacionales. 9. Proyectos que afecten el Sistema de Parques Nacionales Naturales. 10. Proyectos que adelanten las Corporaciones Autónomas Regionales a que hace referencia el numeral 19 del artículo 31 de la presente Ley. 11. Transvase de una cuenca a otra de corrientes de agua que excedan de $2 \mathrm{~m}^{3} / \mathrm{segundo}$ durante los períodos de mínimo caudal. 12. Introducción al país de parentales para la reproducción de especies foráneas de fauna y flora silvestre que 
En los artículos 56 y 57 se alojaron los estudios ambientales en los cuales debe soportarse el otorgamiento de la licencia: por una parte, el diagnóstico ambiental de alternativas y, por otra, el estudio de impacto ambiental.

Grosso modo, el diagnóstico ambiental de alternativas tiene por objeto suministrar información para evaluar y comparar diferentes alternativas ambientales sobre el desarrollo de los proyectos, obras o actividades. La intención es que el peticionario de una licencia aporte a la autoridad competente elementos de juicio para seleccionar una alternativa o alternativas para optimizar y racionalizar el uso de recursos y evitar o minimizar los riesgos, efectos e impactos negativos.

El estudio de impacto ambiental es el instrumento técnico esencial con base en el cual la autoridad ambiental competente toma decisiones para otorgar o no licencias. De acuerdo con MANuel RODRÍGUEZ-BECERRA" ${ }^{21}$, "el estudio de impacto ambiental debe incluir el conjunto detallado de actividades y obras de prevención, mitigación, etc., con sus presupuestos respectivos. Al exigir su ejecución, estos constituyen un aspecto crucial para que la autoridad ambiental haga el seguimiento de su cumplimiento".

De acuerdo con la normativa actual, a ese conjunto de actividades de prevención, mitigación, corrección y compensación, incluidas dentro de la licencia ambiental, se le denomina Plan de Manejo Ambiental, aunque no siempre ha sido así2 ${ }^{2}$.

puedan afectar la estabilidad de los ecosistemas o de la vida salvaje. 13. Las demás que por ser de importancia nacional, se definan en los reglamentos.

21 Manuel Rodríguez-Becerra, La reforma ambiental en Colombia. Anotaciones para la historia de la gestión pública ambiental, 114 (Fundación para la Educación y el Desarrollo Social, FES, Tierra Mar Editores, Bogotá, 1998).

22 De acuerdo con el artículo 1 del Decreto 2041 de 2014 (vigente sobre licencias ambientales), el Plan de Manejo Ambiental se define como: "el conjunto detallado de medidas y actividades que, producto de una evaluación ambiental, están orientadas a prevenir, mitigar, corregir o compensar los impactos y efectos ambientales debidamente identificados, que se causen por el desarrollo de un proyecto, obra o actividad. Incluye los planes de seguimiento, monitoreo, contingencia, y abandono según la naturaleza del proyecto, obra o actividad". Colombia, Decreto 2041 de 2014, por el cual se reglamenta el Título VIII de la Ley 99 de 1993 sobre licencias ambientales, 49.305 Diario Oficial, 15 de octubre de 2014. Disponible en: http://www. alcaldiabogota.gov.co/sisjur/normas/Norma1.jsp?i=59782 


\section{Desarrollo reglamentario de la licencia ambiental en Colombia}

Antes de entrar en consideraciones puntuales sobre cada una de las reglamentaciones expedidas, es necesario anticipar el escenario general desarrollado hasta hoy.

Como se señaló, la primera reglamentación data de agosto de 1994 con el decreto $1753^{23}$. Este reglamento ha sido el de mayor duración; expertos coinciden en reconocerlo como de gran elaboración, teniendo en cuenta su calidad técnica y comprensiva de los fenómenos de deterioro ambiental.

Este decreto fue derogado ocho años después por el 1728 de $2002^{24}$, y este, a su vez, por el 1180 de $2003^{25}$. Más adelante, este corrió la misma suerte como consecuencia de la expedición del Decreto 1220 de $2005^{26}$, el cual fue derogado cinco años después por el 2820 de $2010^{27}$.

En la actualidad, la disposición vigente sobre la materia está en el Decreto 2041 de 15 de octubre de $2014^{28}$, el cual se armoniza con el Decreto único del sector, el 1076 de 26 de mayo de $2015^{29}$.

A los decretos generales es necesario agregarles otros expedidos para regular asuntos puntuales, conexos con la evaluación de impacto ambiental y la licencia. Esos decretos pueden ser clasificados en dos grupos: i) los que establecen mecanismos de control a obras,

23 Colombia, Decreto 1753 de 1994, por el cual se reglamentan parcialmente los Títulos VIII y XII de la Ley 99 de 1993 sobre licencias ambientales, 41.427 Diario Oficial. Disponible en: http://www.alcaldiabogota.gov.co/sisjur/normas/Norma1.jsp?i=1299

24 Colombia, Decreto 1728 de 2002, por el cual se reglamenta el Título VIII de la Ley 99 de 1993 sobre la licencia ambiental. 44.893 Diario Oficial, 7 de agosto de 2002. Disponible en: http:// www.alcaldiabogota.gov.co/sisjur/normas/Norma1.jsp?i=5548

25 Colombia, Decreto 1180 de 2003, por el cual se reglamenta el Título VIII de la Ley 99 de 1993 sobre Licencias Ambientales, 45.185 Diario Oficial, 12 de mayo de 2003. Disponible en: http:// www.alcaldiabogota.gov.co/sisjur/normas/Norma1.jsp?i=8144

26 Colombia, Decreto 1220 de 2005, por el cual se reglamenta el Título VIII de la Ley 99 de 1993 sobre licencias ambientales, 45.890 Diario Oficial, 25 de abril de 2005. Disponible en: http:// www.alcaldiabogota.gov.co/sisjur/normas/Norma1.jsp?i=16316

27 Colombia, Decreto 2820 de 2010, por el cual se reglamenta el Título VIII de la Ley 99 de 1993 sobre licencias ambientales, 47.792 Diario Oficial, 5 de agosto de 2010. Disponible en: http:// www.alcaldiabogota.gov.co/sisjur/normas/Norma1.jsp?i $=45524$

28 Colombia, Decreto 2041 de 2014, por el cual se reglamenta el Título VIII de la Ley 99 de 1993 sobre licencias ambientales, 49.305 Diario Oficial, 15 de octubre de 2014. Disponible en: http:// www.alcaldiabogota.gov.co/sisjur/normas/Norma1.jsp?i=59782

29 Colombia, Decreto 1076 de 2015, Decreto único del Sector Medio Ambiente y Desarrollo Sostenible, 49.523 Diario Oficial, 26 de mayo de 2015. Disponible en: http://www.alcaldiabogota. gov.co/sisjur/normas/Norma1.jsp?i=62511 
proyectos y actividades de impacto mínimo, leve o moderado, es decir, que no producen deterioros graves y, por tanto, no requieren licencia; y, ii) los que modifican aspectos puntuales de los decretos generales con la intención de suprimir o introducir actividades a las listas taxativas incorporadas ${ }^{30}$.

Entre los del primer grupo tenemos el 1421 de $1996^{31}$, por medio del cual se fijó una lista de proyectos, obras o actividades que, al no producir deterioro grave a los recursos naturales o al medio ambiente, se dispuso ejecutar un plan de manejo ambiental para ser controlados por las autoridades ambientales competentes. A pesar de su buena intención, la disposición en la cual se sustentaba fue declarada inexequible por la Corte Constitucional y, por tanto, feneción ${ }^{32}$.

En este primer grupo está también el Decreto 883 de 4 abril de $1997^{33}$, en virtud del cual se definió un instrumento administrativo para controlar actividades que no causasen deterioro grave a los recursos naturales renovables o al medio ambiente $y$, por tanto, no requerían licencia ambiental; así como a proyectos, obras o actividades que formando parte de otros, y que teniendo licencia o plan de manejo, recuperación o restauración ambiental, necesitaban ciertos ajustes o complementos.

El Decreto 883 de 1997 fue bien recibido por la comunidad académica y las organizaciones ambientales; sin embargo, sucumbió ante las presiones gremiales y fue declarado nulo por el Consejo de Estado $^{34}$.

30 No obstante cabe aclarar que, de ordinario, el camino escogido por el gobierno para la supresión de actividades ha sido la expedición de decretos generales.

31 Colombia, Decreto 1421 de 1996, por el cual se reglamenta el artículo 134 del Decreto Ley 2150 de 1995, 42.857 Diario Oficial, 16 de agosto de 1996. Disponible en: https://normativa. colpensiones.gov.co/colpens/docs/decreto_1421_1996.htm

32 El artículo 134 del Decreto 2150 de 1995 señalaba: "Plan de Manejo Ambiental. El gobierno nacional determinará los casos en los cuales bastará la presentación de un plan de manejo ambiental para iniciar actividades. En este caso fijará los requisitos y contenidos de dichos planes de manejo ambiental". Sin embargo, los artículos 133 y 134 fueron declarados inexequibles por la Corte Constitucional. Corte Constitucional, Sentencia C-433-96, 12 de septiembre de 1996, magistrado ponente Eduardo Cifuentes-Muñoz. Disponible en: http:// www.corteconstitucional.gov.co/relatoria/1996/C-433-96.htm

33 Colombia, Decreto 883 de 1997, por el cual se regulan de manera general algunas actividades y se define un instrumento administrativo para la prevención o el control de los factores de deterioro ambiental, 43.013 Diario Oficial, 4 de abril de 1997. Disponible en: http://www.icbf. gov.co/cargues/avance/docs/decreto_0883_1997.htm

34 Consejo de Estado, Sección Primera, Expediente 4500, Sentencia del 26 de febrero de 1998, magistrado ponente Ernesto Rafael-Ariza. Disponible en: http://190.24.134.114:8080/Web 
En cuanto a los del segundo grupo ${ }^{35}$, tenemos los Decretos 2183 de $1996^{36}$ y 1892 de septiembre de $1999^{37}$, los cuales definieron la inclusión de proyectos, obras o actividades sometidos a licencia ambiental; el 1122 de $1999^{38}$ y el 266 de $2000^{39} 40$ tuvieron por finalidad eliminar la licencia ambiental para algunos proyectos y sustituyeron los criterios de deterioro grave y modificaciones considerables al paisaje, por el de impacto significativo, para determinar los casos en que la licencia ambiental fuese requerida.

Como se ve, no hay que ser experto para advertir un escenario recargado y complejo en lo que a la reglamentación del instrumento de control se trata. El embrollo montado por el Estado colombiano requiere de ojo avizor para no perderse entre la maraña de disposiciones que hacen difícil el seguimiento del asunto.

Por ello resulta necesario revisar el alcance de cada una de las modificaciones reglamentarias expedidas y también el contexto económico y político en el que se dio cada una de ellas.

Relatoria/ce/index.xhtml

35 Normalmente, los decretos de este tipo contienen pocos artículos en los cuales solo se ventila la supresión o la inclusión de algún proyecto, obra o actividad. Así por ejemplo, el decreto 2183 de 1996 solo tiene dos artículos, el primero señala una inclusión al régimen general creado con anterioridad: Artículo 1: El numeral 18 del artículo 8 del Decreto 1753 de 1994, quedará así:

"Diseño y establecimientos de complejos y proyectos turísticos, recreacionales y deportivos con excepción de los parques públicos para recreación pasiva y los jardines botánicos. Los parques públicos, sin perjuicio de las disposiciones locales sobre planificación, solo requerirán de la presentación ante la autoridad ambiental respectiva de una información breve y sumaria sobre las características y alcances del proyecto a desarrollar. Los jardines botánicos, por su parte, se someterán únicamente a las prescripciones establecidas en la Ley 299 de 1996 y en sus respectivos decretos reglamentarios". Colombia, Decreto 2183 de 1996, por el cual se modifica parcialmente el Decreto Reglamentario 1753 de 1994 sobre licencias ambientales, 42.933 Diario Oficial, 5 de diciembre de 1996. Disponible en: http://www.alcaldiabogota.gov. co/sisjur/normas/Normal.jsp?i=3352

36 Colombia, Decreto 2183 de 1996, por el cual se modifica parcialmente el Decreto Reglamentario 1753 de 1994 sobre licencias ambientales, 42.933 Diario Oficial, 5 de diciembre de 1996. Disponible en: http://www.alcaldiabogota.gov.co/sisjur/normas/Norma1.jsp?i=3352

37 Colombia, Decreto 1892 de 1999, por la cual se determinan proyectos u obras que requieren de licencia ambiental, 43.727 Diario Oficial, 1 de octubre de 1999. Disponible en: http://www. creg.gov.co/html/Ncompila/htdocs/Documentos/GasNatural/docs/d1892_99.htm

38 Colombia, Decreto 1122 de 1999, por el cual se dictan normas para suprimir trámites, facilitar la actividad de los ciudadanos, contribuir a la eficiencia y eficacia de la Administración Pública y fortalecer el principio de la buena fe, 43.622 Diario Oficial, 29 de junio de 1999. Disponible en: http://www.alcaldiabogota.gov.co/sisjur/normas/Norma1.jsp?i=9208

39 Colombia, Decreto 266 de 2000, por el cual se dictan normas para suprimir y reformar las regulaciones, trámites y procedimientos, 43.906 Diario Oficial, 22 de febrero de 2000. Disponible en: http://www.alcaldiabogota.gov.co/sisjur/normas/Norma1.jsp?i=3281

40 Los dos decretos, el 1122 y el 266 fueron decretos antitrámites, expedidos para suprimir o reformar las regulaciones, procedimientos y trámites de la vida pública nacional. El gobierno aprovechó esta vía para suprimir del control ambiental ciertas actividades antes sometidas. 
Contexto político y económico en las reformas reglamentarias de la licencia ambiental en Colombia

Atendiendo el panorama hasta ahora descrito, es ineludible dedicar unas líneas al contexto político y económico en el cual se dieron las distintas reglamentaciones sobre la licencia ambiental. Lo anterior permitirá profundizar en consideraciones sobre los motivos que han desembocado en el panorama actual de este instrumento.

Le correspondió a César Gaviria-Trujillo (1990-1994) decidir y sustentar ante el Congreso la creación en 1993 de un Ministerio del Medio Ambiente y no un Departamento Administrativo. La decisión final, notablemente influenciada por la activa participación del país en la Cumbre de Río, fue la más acertada.

Al regresar, Gaviria honró sus compromisos ambientales internacionales, ya que no solo impulsó y fue decisivo en la expedición de la ley ambiental en el Congreso, sino que creó el Ministerio desoyendo las voces de diversos sectores económicos que clamaban por la creación de una autoridad de bajo perfil ${ }^{41}$.

Aun cuando el principal objetivo del gobierno Gaviria fue alcanzar una apertura económica enfocada hacia una economía más eficiente y productiva, su plan nacional de desarrollo La revolución pacífica $^{42}$ planteó seis objetivos de política ambiental, con los que buscó comprometer de manera activa a los sectores productivos privados, el gobierno y la ciudadanía para la conservación y recuperación de la base natural del país.

En su gobierno, dio inicio el desarrollo normativo ambiental y en relación con la licencia ambiental, el artículo 52 de la Ley 99 de 1993 estableció la primera lista de actividades, proyectos y obras, todos ellos competencia del Ministerio del Medio Ambiente. En esa reglamentación aparece un conjunto de 13 actividades que, por su impacto, debían ser controladas.

41 De acuerdo con Manuel Rodríguez-Becerra, el cabildeo realizado por los gremios, sobre todo de la Asociación de Industriales de Colombia, ANDI (hoy Asociación Nacional de Empresarios de Colombia, ANDI), presionó fuertemente al Congreso de la República para no aprobar el proyecto para la expedición de Ley 99 de 1993. MANuel RodríGuez-BECERRA, La reforma ambiental en Colombia. Anotaciones para la historia de la gestión pública ambiental, 194-195 (Fundación para la Educación y el Desarrollo Social, FES, Tierra Mar Editores, Bogotá, 1998).

42 Gobierno de César Gaviria-Trujillo, Plan Nacional de Desarrollo 1990-1994, La revolución pacífica. Disponible en: https://www.dnp.gov.co/Plan-Nacional-de-Desarrollo/Paginas/Planesde-Desarrollo-anteriores.aspx 
Por su parte, El salto social ${ }^{43}$, de Ernesto Samper-Pizano (19941998), se presentó como un modelo de desarrollo alternativo a las políticas neoliberales, basado en el progreso del campo para permitir, sin despreciar la importancia del mercado, consolidar un buen gobierno transparente, eficiente y descentralizado.

Recién posesionado Samper, fue expedido el Decreto 1753 de 1994, que no solo estableció la competencia de las autoridades ambientales en materia de licencias, sino que amplió la descripción de los proyectos de competencia del Ministerio señalados en los numerales $1,2,4$ y $5^{44}$ del artículo 7.

Además de lo anterior, agregó nuevas actividades de impacto ambiental, como la generación de energía nuclear, la fabricación de municiones y explosivos, y los casos establecidos en el parágrafo 2 del artículo $7^{45}$.

Durante el gobierno Samper se dieron los pasos necesarios para contar con una política clara y concertada en materia ambiental, la cual se plasmó en el Documento Conpes 2750 de diciembre de $1994^{46}$. Esta Política nacional ambiental, Salto social hacia el de-

43 Gobierno de Ernesto Samper-Pizano, Plan Nacional de Desarrollo 1994-1998, El salto social. Disponible en: https://www.dnp.gov.co/Plan-Nacional-de-Desarrollo/Paginas/Planes-deDesarrollo-anteriores.aspx

44 Artículo 7. Competencia del Ministerio del Medio Ambiente. El Ministerio del Medio Ambiente otorgará de una manera privativa la licencia ambiental en los siguientes casos: 1 . Ejecución de obras y actividades de exploración, explotación, transporte, conducción y transporte de hidrocarburos, construcción de refinerías, refinación de petróleos y los desarrollos petroquímicos que formen parte de un complejo de refinación. 2. Ejecuciones de proyectos de gran minería, entendiendo estos como la exploración, montaje, producción, beneficio, almacenamiento, acopio, transporte, fundición, procesamiento y transformación de minerales, de conformidad con las definiciones y la clasificación de la gran minería contenidas en el Código de Minas. 4. Construcción o ampliación de puertos marítimos de gran calado, entendiéndose por tales aquellos en los cuales pueden atracar embarcaciones de 10.000 o más toneladas de registro neto o con calado igual o superior a 15 pies, o en aquellos en que se moviliza una carga superior a un millón de toneladas al año, aun cuando esta se realice mediante fondeo. 5. Construcciones de instalación, ampliación o mejoramiento de aeropuertos internacionales. Colombia, Decreto 1753 de 1994, por el cual se reglamentan parcialmente los Títulos VIII y XII de la Ley 99 de 1993 sobre licencias ambientales, 41.427 Diario Oficial, 3 de agosto de 1994. Disponible en: http://www.alcaldiabogota.gov.co/sisjur/normas/Norma1.jsp?i=1299

45 Artículo 7. Competencia del Ministerio del Medio Ambiente. El Ministerio del Medio Ambiente otorgará de una manera privativa la licencia ambiental en los siguientes casos: Parágrafo 2. Los proyectos o actividades de mantenimiento de sistemas de control y operación, y reposición de unidades de equipo o de procesos existentes, no requerirán licencia ambiental, siempre y cuando no implique un aumento en la capacidad, o en la producción de contaminantes que incremente el riesgo ambiental o pueda adversamente los sistemas de tratamiento instalados. Tampoco requerirán licencia ambiental los proyectos o actividades que conformen parte del plan de manejo aprobado por la autoridad ambiental.

46 Consejo de Política Económica y Social, Conpes, Documento Conpes 2750, Política nacional ambiental, Salto social hacia el desarrollo humano sostenible (Ministerio de Ambiente, De- 
sarrollo humano sostenible ha sido considerada como la primera política ambiental nacional promulgada luego de la creación del Ministerio del Medio Ambiente; ella reconoce la importancia de fortalecer los mecanismos administrativos de comando y control, en particular, la licencia ambiental.

A pesar de sus conocidas limitaciones de gobernabilidad, Samper fue siempre respetuoso de los acuerdos y compromisos internacionales ambientales suscritos por el país y, en ese sentido, adoptó las medidas necesarias para su cumplimiento.

El gobierno de Andrés Pastrana-Arango (1998-2002) adoptó en su plan nacional de desarrollo Cambios para construir la paz ${ }^{47}$, una política ambiental nacional denominada Proyecto colectivo ambiental; sin embargo, inició las primeras acciones para mermar la fuerza de la licencia.

La política ambiental sectorial de Producción más limpia en agosto de 1997, que había sido expedida al final del gobierno Samper ${ }^{48}$, lo llevó al convencimiento de que era mejor un mal arreglo que un buen pleito y decidió promover la firma de los denominados: Códigos Voluntarios de Autogestión, los cuales buscaron la autorregulación de los sectores económicos, transitando hacia la flexibilización de actividades y procedimientos licenciatorios. Fruto de lo anterior se expidieron los decretos 1892 y 1122 de 1999 y el 266 de 2000.

La paradoja es que los expertos coinciden en afirmar que al menos la primera mitad del gobierno Pastrana ha sido la de mejores resultados para la gestión ambiental. Lo anterior como consecuencia del liderazgo ejercido por el ministro de la época, Juan Mayr (1998-2002), experto ambientalista que logró poner a Colombia en lo más alto de la gestión ambiental internacional.

partamento Nacional de Planeación, DNP, Unidad de Política Ambiental, UPA, Bogotá, 21 de diciembre de 1994). Disponible en: https://colaboracion.dnp.gov.co/CDT/CONPES/ Econ $\% \mathrm{C} 3 \% \mathrm{~B} 3 \mathrm{micos} / 2750$.pdf

47 Gobierno de Andrés Pastrana-Arango, Plan Nacional de Desarrollo 1998-2002, Cambios para construir la paz. Disponible en: https://www.dnp.gov.co/Plan-Nacional-de-Desarrollo/ Paginas/Planes-de-Desarrollo-anteriores.aspx

48 Ministerio de Medio Ambiente, Política nacional de producción más limpia (Bogotá, 1997). Disponible en: https://www.minambiente.gov.co/images/BosquesBiodiversidadyServicios Ecosistemicos/pdf/Normativa/Politicas/polit_produccion_mas_limpia.pdf 
Años después y por los resultados obtenidos se confirma que la Política nacional de producción más limpia, además de flexibilizar la licencia, no fue lo que se esperaba ${ }^{49}$.

Pero, sin duda, la involución en los asuntos ambientales del país (la cual se mantiene hoy in crescendo) y, por supuesto, en relación con la licencia, se dio a partir del gobierno de Álvaro Uribe-Vélez.

Este gobierno tiró por la borda los esfuerzos realizados para contar con un Ministerio del Medio Ambiente y, como consecuencia de la expedición del Decreto 216 de $2003^{50}$, fusionó el Ministerio del ramo con el de Desarrollo para crear el de Ambiente, Vivienda y Desarrollo Territorial, MAVDT, combinación incomprensible que se dijo vino justificada por la visión internacional alcanzada en las más recientes conferencias sobre la materia ${ }^{51}$.

En relación con la licencia, este gobierno fue el responsable de haber derogado el Decreto 1753 de 1994 por cuenta del 1728 de 2002, en el cual, si bien se complementaron las funciones del Ministerio y las CAR, se desglosaron los proyectos que la requerirían, teniendo en cuenta el sector productivo al que pertenecían. Lo anterior llevó

49 De los cuatro principales instrumentos establecidos en esta política sectorial, solo uno se mantiene tras su consagración normativa en la Resolución 1023 de 2005. Nos referimos a las guías ambientales, que en la nomenclatura de la política se denominan códigos voluntarios de autogestión. Por su parte, los otros tres instrumentos: los convenios de producción más limpia; la responsabilidad social empresarial (códigos de comportamiento social) y los nodos (técnicos y académicos) de producción más limpia, hoy son letra muerta. Colombia, Ministerio de Ambiente, Vivienda y Desarrollo Territorial, Resolución 1023 de 2005, por la cual se adoptan guías ambientales como instrumento de autogestión y autorregulación, 45.990 Diario Oficial, 4 de agosto de 2005. Disponible en: http://www.icbf.gov.co/cargues/avance/ docs/resolucion_minambientevdt_1023_2005.htm

50 Colombia, Decreto 216 de 2003, por el cual se determinan los objetivos, la estructura orgánica del Ministerio de Ambiente, Vivienda y Desarrollo Territorial y se dictan otras disposiciones, 45.086 Diario Oficial, 3 de febrero de 2003. Disponible en: http://www.alcaldiabogota.gov.co/ sisjur/normas/Norma1.jsp?i=15710

51 Justificación cierta en gran medida, teniendo en cuenta que la primera década del siglo XXI significó el inicio de los retrocesos frente a la protección del medio ambiente a escala planetaria, si se compara con los espectaculares avances alcanzados a lo largo de la década de los noventa, luego de la realización de la Cumbre de Río en 1992. El atentado de las Torres Gemelas el 9 de septiembre de 2001 y la Cumbre de la Organización de las Naciones Unidas para el Desarrollo Sostenible, en Johannesburgo, Sudáfrica, en septiembre de 2002, constituyen el inicio del fin; la separación total y absoluta del plan de acción definido en la Agenda 21 lograda en Río en 1992. Organización de las Naciones Unidas, ONU, Declaración de Río sobre el Medio Ambiente y el Desarrollo, Cumbre para la Tierra, Río de Janeiro, Brasil, 3-14 de junio de 1992. Disponible en: http://www.un.org/spanish/esa/sustdev/documents/declaracionrio. htm, http://www.un.org/spanish/esa/sustdev/agenda21/agenda21toc.htm. Organización de las Naciones Unidas, ONU, División de Desarrollo Sostenible, Declaración de Johannesburgo sobre el Desarrollo Sostenible, Cumbre de Johannesburgo, Johannesburgo, Sudáfrica, 2-4 de septiembre de 2002. Disponible en: http://www.un.org/spanish/esa/sustdev/WSSDsp_PD.htm 
a la eliminación de la actividad de fabricación de municiones y explosivos como actividad licenciada ante el Ministerio y diecisiete (17) diferentes proyectos, obras o actividades de competencia de las $\mathrm{CAR}^{52}$.

Pero solo un año después de expedido el Decreto 1728, el recién creado MAVDT, por medio del Decreto 1180 de $2003^{53}$, derogó la disposición anterior, arrogándose el otorgamiento de licencia ambiental para la construcción de puertos en la red fluvial nacional y disminuyendo la competencia de las CAR para evaluar los impactos ambientales en cinco fundamentales e importantes actividades ${ }^{54}$.

A pesar de las dos modificaciones realizadas en menos de un año, año y medio después, el gobierno Uribe expidió el Decreto 1220 de 2005, por el cual se dieron nuevas exclusiones ${ }^{55}$.

52 Operación de estaciones de servicio de combustibles, depósitos de combustibles y plantas envasadoras y almacenadoras de gas; construcción de sistemas de acueducto en áreas urbanas para el abastecimiento de agua potable a más de 5.000 usuarios; construcción y operación de sistemas de alcantarillado, interceptores marginales, sistemas y estaciones de bombeo; diseño y establecimiento de complejos y distritos o ciudadelas industriales y zonas francas; diseño y establecimiento de complejos y proyectos turísticos recreacionales y deportivos; desarrollo de parcelaciones, loteos, condominios y conjuntos habitacionales en zonas donde no haya un plan de ordenamiento de uso del suelo aprobado por la Corporación Autónoma Regional correspondiente; construcción de obras y desarrollo de las siguientes actividades, cuando no haya un plan de ordenamiento de uso del suelo aprobado por las autoridades municipales o distritales y por la respectiva autoridad ambiental competente: a) hospitales; b) cementerios; c) centros de acopio para almacenamiento y distribución de alimentos; d) sistemas de transporte masivo; e) construcción, ampliación, modificación, adecuación y operación de terminales para el transporte terrestre de pasajeros y carga; industria manufacturera de productos alimenticios; industria manufacturera de textiles, prendas de vestir y cuero, industria manufacturera de madera y muebles; industria manufacturera de papel, imprentas y editoriales; industria manufacturera de sustancias químicas, derivados del petróleo y del carbón, y el caucho; industria manufacturera de productos minerales no metálicos, excepto el petróleo y el carbón; industria manufacturera metálica básica; industria manufacturera de productos metálicos, maquinaria y equipos; manipulación genética y producción de microorganismos con fines comerciales; obras o actividades que requieren concesión, licencia o autorización de la Dirección General Marítima, DIMAR, o de la Superintendencia General de Puertos.

53 Colombia, Decreto 1180 de 2003, por el cual se reglamenta el Título VIII de la Ley 99 de 1993 sobre Licencias Ambientales, 45.185 Diario Oficial, 12 de mayo de 2003. Disponible en: http:// www.alcaldiabogota.gov.co/sisjur/normas/Normal.jsp?i=8144

54 El artículo 9, competencia de las corporaciones autónomas regionales, 1) Estableció una limitación en cuanto al otorgamiento de la licencia para los proyectos relacionados con el tendido de líneas de transmisión, en el sentido de que solo se haría exigible para aquellos sistemas de transmisión que operan a tensiones menores de $220 \mathrm{~kW}$. En los decretos que le precedieron no se hacía distinción en relación con los valores de tensión y, por tanto, todo proyecto requería la obtención de licencia. 2) Se eliminó como proyecto sujeto a licencia lo relacionado con las "operaciones de by-pass de arena". 3) Se eliminó la construcción y operación de aeropuertos de nivel regional y pistas de fumigación. 4) Se eliminó la ejecución de obras públicas en la red fluvial; y, además, 5) se eliminó el trasplante de especies, subespecies o variedades de fauna acuática entre cuencas no conectadas.

55 En relación con las competencias del MAVDT, limitó el otorgamiento de licencia para los 
Sin duda, la presidencia de Uribe entendió mal sus compromisos de gobierno; sus dos planes de desarrollo ${ }^{56}$, pero sobre todo el primero - Hacia un estado comunitario - apostó por alcanzar altos niveles de inversión extranjera directa por medio de la denominada Confianza inversionista, que consistió en atraer capitales extranjeros al país componiendo lo necesario para que estos tuviesen ventajas comparativas que les mostraran un panorama atractivo y seguro de inversión ${ }^{57}$. Sin embargo, no solo hubo equívocos en los mecanismos adoptados, sino también en el tipo de inversión a promover: esta se tomó un grado excesivo de confianza al punto de crecer de forma laxa y descontrolada en actividades de enorme impacto ambiental, como la minería.

El segundo mandato de Álvaro Uribe-Vélez significó una continuación de las políticas promulgadas durante su primer gobierno, en el cual se hizo evidente la primacía de una visión de crecimiento económico en vez de una visión de desarrollo sostenible, tal como lo establece la Carta Política de $1991^{58}$.

casos de cierre de brazos y madreviejas, cuando estas estén activas, es decir, anteriormente no se distinguía el estado en que debían encontrarse estas redes fluviales. Por su parte y para el caso de las competencias de las CAR, eliminó la fabricación de explosivos, pólvoras y productos pirotécnicos como actividades sujetas al otorgamiento de la licencia ambiental. Colombia, Decreto 1220 de 2005, por el cual se reglamenta el Título VIII de la Ley 99 de 1993 sobre licencias ambientales, 45.890 Diario Oficial, 25 de abril de 2005. Disponible en: http:// www.alcaldiabogota.gov.co/sisjur/normas/Norma1.jsp?i=16316

56 Gobierno de Álvaro Uribe-Vélez, primer período, Plan Nacional de Desarrollo 2002-2006, Hacia un estado comunitario. Disponible en: https://www.dnp.gov.co/Plan-Nacional-deDesarrollo/Paginas/Planes-de-Desarrollo-anteriores.aspx. Gobierno de Álvaro Uribe-Vélez, segundo período, Plan Nacional de Desarrollo 2006-2010, Estado comunitario. Disponible en: https://www.dnp.gov.co/Plan-Nacional-de-Desarrollo/Paginas/Planes-de-Desarrolloanteriores.aspx

57 No en balde este gobierno inició la negociación de algunos de los 18 Acuerdos de Libre Comercio, 13 de los cuales están vigentes y otros 5 en consultas y/o procesos de adopción. Así mismo, se expidió la Ley 963 de 2005 que regula los denominados Contratos de Estabilidad Jurídica, según los cuales, se busca promover inversiones nuevas y de ampliar las existentes en el territorio nacional, de tal suerte que si durante la vigencia de la inversión se modifica en forma adversa alguna de las normas que haya sido identificada en los contratos como determinante de la inversión, los inversionistas tendrán derecho a que se les continúen aplicando esas normas por el término de duración del contrato respectivo. Pero quizás lo más determinante fue el tipo de inversión que el país promovió y aceptó. Durante la finalización del primer gobierno de Uribe y durante la mitad de su segundo mandato, el $86 \%$ de la inversión extranjera directa, IED, en Colombia fue en el sector de las minas. Colombia, Ley 963 de 2005, por la cual se instaura una ley de estabilidad jurídica para los inversionistas en Colombia, 45.963 Diario Oficial, 8 de julio de 2005. Disponible en: http://www.secretariasenado.gov.co/senado/ basedoc/ley_0963_2005.html

58 El artículo 80 de la Constitución Política señala que es deber del Estado planificar el manejo y aprovechamiento de los recursos naturales, para garantizar su desarrollo sostenible, su conservación, restauración o sustitución. Además, deberá prevenir y controlar los factores de 
Por último, a pesar de representar ideas de gobierno antagónicas, el gobierno de Juan Manuel Santos ha sido más de lo mismo en lo ambiental. Prosperidad para todos ${ }^{59}$ recogió las mismas banderas, aunque se diga que son diferentes.

Teniendo en cuenta lo anterior, y bajo la premisa de que la protección del ambiente se toma en muchos casos como traba para el "desarrollo", recién entrado el gobierno de Álvaro Uribe-Vélez se despidió con otra derogación a la reglamentación de la licencia, esta vez, por cuenta del Decreto 2820 de 5 de agosto de $2010^{60}$.

El Decreto 2820 de 2010 alteró las competencias ya establecidas, con lo que se demostró una vez más la intención de flexibilizar el otorgamiento de las licencias. Así las cosas, se establecieron nuevas modificaciones a los proyectos, obras o actividades sometidos a licenciamiento ${ }^{61}$.

deterioro ambiental, imponer las sanciones legales y exigir la reparación de los daños causados (las negrillas son nuestras). Así mismo, cooperará con otras naciones en la protección de los ecosistemas situados en las zonas fronterizas. Colombia, Constitución Política, segunda edición corregida, 116 Gaceta Constitucional, 20 de julio de 1991. Disponible en: http://www. secretariasenado.gov.co/senado/basedoc/constitucion_politica_1991.html

59 Gobierno de Juan Manuel Santos, primer período, Plan Nacional de Desarrollo 2010-2014: Prosperidad para todos. Disponible en: https://www.dnp.gov.co/Plan-Nacional-de-Desarrollo/ PND-2010-2014/Paginas/Plan-Nacional-De-2010-2014.aspx

60 Frente a la protección ambiental, la administración Santos ha sido de notables ambivalencias, pero sobresale lo negativo. Si bien con la expedición de la ley 1444 de 2011 se regresó al Ministerio de Ambiente, esta vez acompañado del apellido "Desarrollo Sostenible", los ministros colocados allí para encaminar la defensa de este derecho colectivo han sido personas sin formación, ni conocimiento en la materia. Las reformas legales y reglamentarias promovidas o expedidas por el gobierno han sido regresivas en materia de protección ambiental, entre las cuales sobresalen las relativas a la denominada "minería sostenible", la exoneración de evaluación ambiental para la ampliación de la infraestructura vial (4G), el poco respaldo económico para el mantenimiento y/o restauración del sistema de áreas protegidas y, en lo que aquí es competente analizar, la flexibilización al único instrumento de evaluación de impacto ambiental con el que cuenta el país.

61 En relación con las competencias que venían del Ministerio de Ambiente, Vivienda y Desarrollo Territorial, se incluyeron los proyectos de exploración sísmica en las áreas marinas del territorio nacional, cuando sean realizadas a profundidades inferiores a 200 metros. La pregunta es: ¿y el resto de exploraciones? En relación con el sector eléctrico, se excluyeron los proyectos de exploración o uso de fuentes de energía con capacidad inferior a $3 \mathrm{MW}$, anteriormente todos los proyectos — sin importar la capacidad — debían ser licenciados. Se exceptuaron de la licencia la importación de pesticidas en los siguientes casos: plaguicidas de origen biológico elaborados con base en extractos naturales, pesticidas o plaguicidas veterinarios, de uso tópico para mascotas y los accesorios de uso externo, como orejeras, collares, narigueras, etc. y plaguicidas para uso doméstico en presentación o empaque individual. En cuanto a las competencias de las CAR, se llevaron a cabo las siguientes modificaciones: para las centrales generadoras de energía eléctrica, el decreto establece que solo se requerirá licencia cuando se trate de la construcción y operación de centrales generadoras de energía a partir del recurso hídrico con una capacidad menor a $100 \mathrm{MW}$; exceptuando las pequeñas hidroeléctricas destinadas a operar en zonas no interconectadas (ZNI) y cuya capacidad sea igual o menor a $10 \mathrm{MW}$. Se eliminó el control a la estabilización de playas y las entradas 
Al comenzar su segundo período de gobierno, el presidente Santos expidió un nuevo decreto, el 2041 de 15 de octubre de 2014, el cual entró en vigencia el 1 de enero de 2015 en el que se observa una nueva disminución al uso de la licencia ambiental, que a su vez fue totalmente derogado por el Decreto 1076 de 2015, compilatorio de las normas ambientales.

Antes es pertinente anotar que mediante el Decreto 3573 de 27 de septiembre de 2011, el gobierno Santos creó la Autoridad Nacional de Licencias Ambientales, ANLA y le otorgó competencias para otorgar o negar las licencias, permisos y trámites ambientales de competencia del Ministerio de Ambiente y Desarrollo Sostenible ${ }^{62}$. El Decreto 2041 de 2014 establecía en su artículo 8 las competencias de la ANLA para el otorgamiento de licencias ambientales (hoy artículo 2.2.2.3.2.2 del Decreto 1076 de 2015). Este artículo señaló nuevas modificaciones, tanto en las licencias de la ANLA como de las $\mathrm{CAR}^{63}$.

costeras, así como la creación de playas artificiales y dunas.

62 Esa es la nueva denominación que la Ley 1444 de 2011 dio al Ministerio del ramo. En los artículos 12 y 13 de esa Ley se dispone de lo necesario para reorganizar el sistema institucional ambiental en el país: el 12 señala la reorganización del ministerio el cual pasará a denominarse Ministerio de Ambiente y Desarrollo Sostenible, el cual continuará cumpliendo los objetivos y funciones señalados en las normas vigentes, salvo en lo concerniente a la vivienda, el desarrollo territorial y el agua potable y el saneamiento, los cuales pasaron al por primera vez creado Ministerio de Vivienda, Ciudad y Territorio. Por su parte, el artículo 13 señala que el Sector Administrativo del Medio Ambiente y el Desarrollo Sostenible estará integrado por el Ministerio de Ambiente y Desarrollo Sostenible, las Superintendencias y demás entidades que la Ley defina como adscritas o vinculadas al mismo. Colombia, Ley 1444 de 2011, por medio de la cual se escinden unos Ministerios, se otorgan precisas facultades extraordinarias al Presidente de la República para modificar la estructura de la Administración Pública y la planta de personal de la Fiscalía General de la Nación y se dictan otras disposiciones, 48.059 Diario Oficial, 4 de mayo de 2011. Disponible en: http://www.secretariasenado.gov.co/senado/ basedoc/ley_1444_2011.html

63 Una primera modificación se evidencia en los proyectos de exploración y uso de fuentes de energía alternativa virtualmente contaminantes, puesto que anteriormente se exigía una capacidad superior de $3 \mathrm{MW}$, para ser sujeto a licenciamiento ambiental, mientras que con el decreto se exige una capacidad instalada superior o igual cien (100) MW; ampliándose así significativamente los proyectos que se exoneran del instrumento de manejo ambiental. Adicionalmente, de la lista de proyectos sujeto a licenciamiento se eliminan las obras de mantenimiento de los canales de acceso a puertos marítimos. Finalmente y como última función atribuida a la ANLA, se observa un cambio en las competencias para el establecimiento de zoocriaderos que impliquen el manejo de Especies listadas en los Apéndices de la Convención sobre el Comercio Internacional de especies Amenazadas de Fauna y Flora Silvestre (CITES). International Union for Conservation of Nature, IUCN, Convención sobre el Comercio Internacional de Especies Amenazadas de Fauna y Flora Silvestre (CITES), firmada en Washington el 3 de marzo de 1973, enmendada en Bonn, el 22 de junio de 1979, enmendada en Gaborone, el 30 de abril de 1983. Disponible en: https://cites.org/esp/disc/text. php. Por su parte, y en relación con las competencias de las CAR se señaló la exclusión del tendido de líneas del sistema de transmisión regional conformado por el conjunto de líneas 
En todos los casos señalados, las modificaciones a la licencia ambiental se han dado por medio de decretos que no cuentan con apéndices o anexos técnicos, sin motivos o motivación sobre los cambios realizados; en ninguno de los casos hay una evaluación técnica de los impactos ambientales que producen o pueden producir las actividades o proyectos que entran o salen de las listas.

La única razón que salta a la vista es la comprobación de que el país sigue sin contar con una política ambiental clara en el presente y hacia el futuro y que percibe el ambiente como residual en las agendas de los gobiernos de turno. La protección ambiental se sigue viendo como una talanquera de la "modernización" y el "desarrollo", cada vez que hay que echar mano de algo que se puede limitar o suprimir, el ambiente es primera opción.

Ejemplos de lo anterior son la realidad minera y de transporte. En la última modificación por cuenta del Decreto 2041 de 2014 (hoy Decreto 1076 de 2015), mejor conocido como de licencias exprés, se redujeron los tiempos a la mitad para la evaluación de las licencias en el sector minero, toda vez que el otorgamiento de las licencias es perentorio por la necesidad de extracción de recursos.

En ese sentido y sin ser un fenómeno exclusivo de Colombia, la minería y el sector energético se han convertido en los principales focos de atención de las economías emergentes para impulsar su desarrollo. Esta situación se evidencia en Colombia con la implementación de un modelo de desarrollo extractivo mediante la multiplicación de los títulos mineros y la puesta en marcha de las actividades mineras en todo el país ${ }^{64}$.

En cuanto al régimen de licenciamiento en el sector de la infraestructura del transporte, los parágrafos 1 y 2 del artículo 1 del Decreto 769 de $2014^{65}$ —reglamentario de la Ley 1682 de 22 de

con sus módulos de conexión y/o subestaciones, que operan a menores a cincuenta (50) kV. Colombia, Decreto 2041 de 2014, por el cual se reglamenta el Título VIII de la Ley 99 de 1993 sobre licencias ambientales, 49.305 Diario Oficial, 15 de octubre de 2014. Disponible en: http:// www.alcaldiabogota.gov.co/sisjur/normas/Norma1.jsp?i=59782

64 Rodrigo E. Negrete-Montes, Capitulo 1, Derechos, minería y conflictos. Aspectos normativos, en Minería en Colombia, Derechos, políticas públicas y gobernanza, 23-56 (LuIs JoRGE Garay-Salamanca, dir., Contraloría General de la República, Bogotá, 2013). Disponible en: http://www.contraloriagen.gov.co/documents/10136/182119332/Libro_mineria_sep3_2013. pdf/65bf77a0-8b0b-430a-9726-dad0e72639c6

65 Colombia, Decreto 769 de 2014, por el cual se listan las actividades de mejoramiento en proyectos de infraestructura de transporte, 49.130 Diario Oficial, 22 de abril de 2014. Disponible en: http://wsp.presidencia.gov.co/Normativa/Decretos/2014/Documents/ABRIL/22/DECRETO 
noviembre de $2013^{66}$, sobre medidas y disposiciones para los proyectos de infraestructura de transporte - señalan, en su orden, lo siguiente: "Parágrafo 1: "La construcción de segundas calzadas, la construcción de túneles con sus accesos o la construcción de carreteras incluyendo puentes y demás infraestructura asociada a la misma requerirán de la expedición de la correspondiente licencia ambiental. Parágrafo 2: No obstante el parágrafo anterior, las segundas calzadas podrán ser consideradas como actividades de mejoramiento, en aquellos eventos en que la autoridad ambiental así lo determine".

Más adelante la ley 1682 de 2013 definió en su artículo 44 que los proyectos de mantenimiento, los proyectos de rehabilitación y los proyectos de mejoramiento no requieren licencia ambiental ${ }^{67}$. Teniendo en cuenta lo anterior, gran cantidad de proyectos de infraestructura del transporte priorizados por el Plan de Desarrollo son presentados hoy, a pesar de su impacto e importancia, como meros mejoramientos, rehabilitaciones o mantenimientos, cuando en esencia, implican la realización de nuevos proyectos que deberían estar sujetos a evaluación ambiental.

El segundo ejemplo guarda relación con el compromiso del gobierno con la modernización de la infraestructura del transporte, a partir de las denominadas Autopistas de la Prosperidad, 4G o Cuarta Generación, y la construcción de segundas y dobles calzadas por todo el país.

\%20769\%20DEL\%2022\%20DE\%20ABRIL\%20DE\%202014.pdf, http://camacol.co/sites/ default/files/base_datos_juridico/DECRETO $\% 20$ MINAMBIENTE $\% 20$ NACIONAL $\% 20$ $769 \% 20 \mathrm{DE} \% 202014 . \mathrm{pdf}$

66 Colombia, Ley 1682 de noviembre de 2013, por la cual se adoptan medidas y disposiciones para los proyectos de infraestructura de transporte y se conceden facultades extraordinarias, 48.987 Diario Oficial, 27 de noviembre de 2013. Disponible en: http://www.secretariasenado. gov.co/senado/basedoc/ley_1682_2013.html

67 El artículo 44 de la Ley 1682 de 2013 señala: "Los siguientes proyectos de infraestructura de transporte no requerirán licencia ambiental: a) proyectos de mantenimiento; b) proyectos de rehabilitación; c) proyectos de mejoramiento.

Para el debido cumplimiento de la presente disposición, el gobierno nacional, que para estos efectos se entiende conformado por los Ministerios de Transporte y Ambiente, en coordinación con la Autoridad Nacional de Licencias Ambientales, reglamentará en un término máximo de noventa (90) días calendario, a partir de la fecha de expedición de esta ley, el listado de actividades de mejoramiento en proyectos de infraestructura de transporte.

Parágrafo. En el evento que una o más actividades de mejoramiento requiera permisos o autorizaciones ambientales, la entidad pública responsable del proyecto de infraestructura de transporte o quien haga sus veces, deberá tramitarlos y obtenerlos, cuando a ello haya lugar". 
En todo ello, la evaluación con carácter preventivo y protector del principal patrimonio de los colombianos, se soslaya, sin más. 


\section{CONCLUSIONES}

Teniendo en cuenta lo señalado a lo largo de este escrito, es posible afirmar la hipótesis planteada, en el sentido de que la licencia ambiental se ha convertido en un instrumento de comando y control por excepción, sujeta a los vaivenes de las pretensiones del gobierno de turno, producto de la falta de una política de Estado sobre la materia.

Las continuas modificaciones sufridas por la institución dan cuenta de que estas han tenido como fundamento la fuerte influencia de los intereses económicos sobre las decisiones políticas en general y ambientales en particular.

Al comparar lo alcanzado por el Estado colombiano frente a experiencias foráneas bien concebidas y consolidadas, como la europea, el modelo adoptado por el país es del mínimo control que choca - de manera paradójica - con la historia de protección desplegada por Colombia en el contexto internacional, sobre todo durante la parte final del siglo XX.

Lo peor es que mientras se aboga por que la senda del desarrollo tenga en cuenta los objetivos que imprime la sostenibilidad ${ }^{68}$, para el Estado colombiano prima la racionalidad economicista; se ha demostrado cómo los instrumentos de control para el desarrollo de proyectos o actividades son cada vez más laxos, permisivos y regresivos.

68 En septiembre de este año, la ONU se reunirá en la sede de la Organización en Nueva York, durante la Cumbre de Desarrollo Sostenible del 25 al 27 de septiembre de 2016, para hacer seguimiento al más importante compromiso internacional por establecer una senda de desarrollo común y global para la mayoría de las naciones del planeta: los Objetivos de Desarrollo del Milenio, ODM. Sin embargo, ya se ha anunciado que la cumbre servirá, además, para relanzar una nueva hoja de ruta mundial a mediano plazo que incluirá la protección y mejora de la calidad ambiental y la mitigación y adaptación al cambio climático, como uno de sus pilares. Los objetivos pasarán a llamarse: Objetivos de Desarrollo Sostenible. http://www. un.org/sustainabledevelopment/es/summit/ 


\section{BIBLIOGRAFÍA}

\section{Libros}

Betancor-Rodríguez, Andrés, Instituciones de derecho ambiental (La Ley, Madrid, 2001).

Brañes, Raúl, Manual de derecho ambiental mexicano (Fundación Mexicana para la Educación Ambiental, Fondo de Cultura Económica, FCE, México, 1997).

Latorre, Virgilio, Bases metodológicas de la investigación jurídica (Tirant lo Blanch, Valencia, 2011).

Rodríguez-Becerra, Manuel, La reforma ambiental en Colombia. Anotaciones para la historia de la gestión pública ambiental (Fundación para la Educación y el Desarrollo Social, FES, Tierra Mar Editores, Bogotá, 1998).

\section{Colaboraciones en obras colectivas}

Negrete-Montes, Rodrigo E., Capítulo 1, Derechos, minería y conflictos. Aspectos normativos, en Minería en Colombia, Derechos, politicas públicas y gobernanza, 23-56 (Luis Jorge Garay-Salamanca, dir., Contraloría General de la República, Bogotá, 2013). Disponible en: http://www.contraloriagen.gov.co/ documents/10136/182119332/Libro_mineria_sep3_2013.pdf/65bf77a0-8b0b-430a9726-dad0e72639c6

\section{Tratados internacionales}

International Union for Conservation of Nature, IUCN, Convención sobre el Comercio Internacional de Especies Amenazadas de Fauna y Flora Silvestre (CITES), firmada en Washington el 3 de marzo de 1973, enmendada en Bonn, el 22 de junio de 1979, enmendada en Gaborone, el 30 de abril de 1983. Disponible en: https://cites.org/esp/disc/text.php

Organización de las Naciones Unidas, ONU, Declaración de la Conferencia de las Naciones Unidas sobre el Medio Humano, Estocolmo, Suecia, 5-16 de junio de 1972. Disponible en: http://www.unep.org/documents.multilingual/default.asp ?documentid $=97 \&$ articleid $=1503$

Organización de las Naciones Unidas, ONU, Declaración de Río sobre el Medio Ambiente y el Desarrollo, Cumbre para la Tierra, Río de Janeiro, Brasil, 3-14 de junio de 1992. Disponible en: http://www.un.org/spanish/esa/sustdev/ documents/declaracionrio.htm, http://www.un.org/spanish/esa/sustdev/ agenda21/agenda21toc.htm

Organización de las Naciones Unidas, ONU, División de Desarrollo Sostenible, Declaración de Johannesburgo sobre el Desarrollo Sostenible, Cumbre de Johannesburgo, Johannesburgo, Sudáfrica, 2-4 de septiembre de 2002. Disponible en: http://www.un.org/spanish/esa/sustdev/WSSDsp_PD.htm 


\section{Normatividad internacional}

Unión Europea, Directiva Comunitaria 85/337/CEE del Consejo, 27 de junio de 1985, relativa a la evaluación de las repercusiones de determinados proyectos públicos y privados sobre el medio ambiente [modificaciones Directiva 97/11/CE, Directiva 2001/42/CE y Directiva 2001/42/CE]. Disponible en: http://eur-lex.europa.eu/ legal-content/ES/TXT/?uri=URISERV\%3A128163

\section{Normatividad colombiana}

Colombia, Constitución Política, segunda edición corregida, 116 Gaceta Constitucional, 20 de julio de 1991. Disponible en: http://www.secretariasenado.gov.co/senado/ basedoc/constitucion_politica_1991.html

Colombia, Decreto Ley 2811 de 1974, por el cual se dicta el Código Nacional de Recursos Naturales Renovables y de Protección al Medio Ambiente, 34.243 Diario Oficial, 18 de diciembre de 1974. Disponible en: http://www.alcaldiabogota.gov.co/sisjur/ normas/Norma1.jsp?i $=1551 \# 0$

Colombia, Decreto 1753 de 1994, por el cual se reglamentan parcialmente los Títulos VIII y XII de la Ley 99 de 1993 sobre licencias ambientales, 41.427 Diario Oficial, 3 de agosto de 1994. Disponible en: http://www.alcaldiabogota.gov.co/sisjur/ normas/Norma1.jsp?i=1299

Colombia, Decreto 1421 de 1996, por el cual se reglamenta el artículo 134 del Decreto Ley 2150 de 1995, 42.857 Diario Oficial, 16 de agosto de 1996. Disponible en: https://normativa.colpensiones.gov.co/colpens/docs/decreto_1421_1996.htm

Colombia, Decreto 2183 de 1996, por el cual se modifica parcialmente el Decreto Reglamentario 1753 de 1994 sobre licencias ambientales, 42.933 Diario Oficial, 5 de diciembre de 1996. Disponible en: http://www.alcaldiabogota.gov.co/sisjur/ normas/Norma1.jsp?i=3352

Colombia, Decreto 883 de 1997, por el cual se regulan de manera general algunas actividades y se define un instrumento administrativo para la prevención o el control de los factores de deterioro ambiental, 43.013 Diario Oficial, 4 de abril de 1997. Disponible en: http://www.icbf.gov.co/cargues/avance/docs/ decreto_0883_1997.htm

Colombia, Decreto 1122 de 1999, por el cual se dictan normas para suprimir trámites, facilitar la actividad de los ciudadanos, contribuir a la eficiencia y eficacia de la Administración Pública y fortalecer el principio de la buena fe, 43.622 Diario Oficial, 29 de junio de 1999. Disponible en: http://www.alcaldiabogota.gov.co/ sisjur/normas/Norma1.jsp?i=9208

Colombia, Decreto 1892 de 1999, por la cual se determinan proyectos u obras que requieren de licencia ambiental, 43.727 Diario Oficial, 1 de octubre de 1999. Disponible en: http://www.creg.gov.co/html/Ncompila/htdocs/Documentos/ GasNatural/docs/d1892_99.htm

Colombia, Decreto 266 de 2000, por el cual se dictan normas para suprimir y reformar las regulaciones, trámites y procedimientos, 43.906 Diario Oficial, 22 de febrero de 2000. Disponible en: http://www.alcaldiabogota.gov.co/sisjur/normas/Norma1. 
jsp?i=3281

Colombia, Decreto 216 de 2003, por el cual se determinan los objetivos, la estructura orgánica del Ministerio de Ambiente, Vivienda y Desarrollo Territorial y se dictan otras disposiciones, 45.086 Diario Oficial, 3 de febrero de 2003. Disponible en: http://www.alcaldiabogota.gov.co/sisjur/normas/Norma1.jsp?i=15710

Colombia, Decreto 1728 de 2002, por el cual se reglamenta el Título VIII de la Ley 99 de 1993 sobre la licencia ambiental. 44.893 Diario Oficial, 7 de agosto de 2002. Disponible en: http://www.alcaldiabogota.gov.co/sisjur/normas/Norma1. jsp?i=5548

Colombia, Decreto 1180 de 2003, por el cual se reglamenta el Título VIII de la Ley 99 de 1993 sobre Licencias Ambientales, 45.185 Diario Oficial, 12 de mayo de 2003. Disponible en: http://www.alcaldiabogota.gov.co/sisjur/normas/Normal. jsp?i=8144

Colombia, Decreto 1220 de 2005, por el cual se reglamenta el Título VIII de la Ley 99 de 1993 sobre licencias ambientales, 45.890 Diario Oficial, 25 de abril de 2005. Disponible en: http://www.alcaldiabogota.gov.co/sisjur/normas/Norma1. jsp?i=16316

Colombia, Decreto 2820 de 2010, por el cual se reglamenta el Título VIII de la Ley 99 de 1993 sobre licencias ambientales, 47.792 Diario Oficial, 5 de agosto de 2010. Disponible en: http://www.alcaldiabogota.gov.co/sisjur/normas/Norma1. jsp?i=45524

Colombia, Decreto 3573 de 2011, por el cual se crea la Autoridad Nacional de Licencias Ambientales -ANLA- y se dictan otras disposiciones, 48.205 Diario Oficial, 27 de septiembre de 2011. Disponible en: http://www.secretariasenado.gov.co/ senado/basedoc/decreto_3573_2011.html

Colombia, Decreto 769 de 2014, por el cual se listan las actividades de mejoramiento en proyectos de infraestructura de transporte, 49.130 Diario Oficial, 22 de abril de 2014. Disponible en: http://wsp.presidencia.gov.co/Normativa/ Decretos/2014/Documents/ABRIL/22/DECRETO\%20769\%20DEL\%2022\%20 DE\%20ABRIL\%20DE\%202014.pdf, http:/camacol.co/sites/default/files/ base_datos_juridico/DECRETO $\% 20$ MINAMBIENTE $\% 20$ NACIONAL $\% 20$ 769\%20DE\%202014.pdf

Colombia, Decreto 2041 de 2014, por el cual se reglamenta el Título VIII de la Ley 99 de 1993 sobre licencias ambientales, 49.305 Diario Oficial, 15 de octubre de 2014. Disponible en: http://www.alcaldiabogota.gov.co/sisjur/normas/Norma1. jsp?i $=59782$

Colombia, Decreto 1076 de 2015, Decreto único del Sector Medio Ambiente y Desarrollo Sostenible, 49.523 Diario Oficial, 26 de mayo de 2015. Disponible en: http://www. alcaldiabogota.gov.co/sisjur/normas/Normal.jsp?i=62511

Colombia, Ley 23 de 1973, por la cual se conceden facultades extraordinarias al Presidente de la República para expedir el Código de Recursos Naturales y protección al medio ambiente y se dictan otras disposiciones, 19 de diciembre de 1973. Disponible en: http://www.alcaldiabogota.gov.co/sisjur/normas/Norma1. jsp?i=9018

Colombia, Ley 99 de 1993, Ley General Ambiental de Colombia, por la cual se crea el 
Ministerio del Medio Ambiente, se reordena el sector público encargado de la gestión y conservación del medio ambiente y los recursos naturales renovables, se organiza el Sistema Nacional Ambiental, SINA, y se dictan otras disposiciones, 41.146 Diario Oficial, 22 de diciembre de 1993. Disponible en: http://www. secretariasenado.gov.co/senado/basedoc/ley_0099_1993.html

Colombia, Ley 768 de 2002, por la cual se adopta el régimen político, administrativo y fiscal de los distritos portuario e industrial de Barranquilla, Turístico y Cultural de Cartagena de Indias y Turístico, Cultural e Histórico de Santa Marta, 44.893 Diario Oficial, 7 de agosto de 2002. Disponible en: http://www.secretariasenado. gov.co/senado/basedoc/ley_0768_2002.html

Colombia, Ley 963 de 2005, por la cual se instaura una ley de estabilidad jurídica para los inversionistas en Colombia, 45.963 Diario Oficial, 8 de julio de 2005. Disponible en: http://www.secretariasenado.gov.co/senado/basedoc/ley_0963_2005.html

Colombia, Ley 1444 de 2011, por medio de la cual se escinden unos Ministerios, se otorgan precisas facultades extraordinarias al Presidente de la República para modificar la estructura de la Administración Pública y la planta de personal de la Fiscalía General de la Nación y se dictan otras disposiciones, 48.059 Diario Oficial, 4 de mayo de 2011. Disponible en: http://www.secretariasenado.gov.co/ senado/basedoc/ley_1444_2011.html

Colombia, Ley 1617 de 2013, por la cual se expide el Régimen para los Distritos Especiales, 48.695 Diario Oficial, 5 de febrero de 2013. Disponible en: http:// www.secretariasenado.gov.co/senado/basedoc/ley_1617_2013.html

Colombia, Ley 1682 de noviembre de 2013, por la cual se adoptan medidas y disposiciones para los proyectos de infraestructura de transporte y se conceden facultades extraordinarias, 48.987 Diario Oficial, 27 de noviembre de 2013. Disponible en: http://www.secretariasenado.gov.co/senado/basedoc/ley_1682_2013.html

Colombia, Ministerio de Ambiente, Vivienda y Desarrollo Territorial, Resolución 1023 de 2005, por la cual se adoptan guías ambientales como instrumento de autogestión y autorregulación, 45.990 Diario Oficial, 4 de agosto de 2005. Disponible en: http://www.icbf.gov.co/cargues/avance/docs/resolucion_ minambientevdt_1023_2005.htm

\section{Jurisprudencia colombiana}

Consejo de Estado, Sección Primera, Expediente 4500, Sentencia del 26 de febrero de 1998, magistrado ponente Ernesto Rafael-Ariza. Disponible en: http://190.24.134.114:8080/WebRelatoria/ce/index.xhtml

Corte Constitucional, Sentencia C-433-96, 12 de septiembre de 1996, magistrado ponente Eduardo Cifuentes-Muñoz. Disponible en: http://www.corteconstitucional.gov. co/relatoria/1996/C-433-96.htm

Corte Constitucional, Sentencia C-1316-00, 26 de septiembre de 2000, magistrado ponente Carlos Gaviria-Díaz. Disponible en: http://www.corteconstitucional. gov.co/relatoria/2000/C-1316-00.htm

Corte Constitucional, Sentencia T-411-92, 17 de junio de 1992, magistrado ponente Alejandro Martínez-Caballero. Disponible en: http://www.corteconstitucional. 
gov.co/relatoria/1992/T-411-92.htm

\section{Planes nacionales de desarrollo}

Gobierno de Álvaro Uribe-Vélez, primer período, Plan Nacional de Desarrollo 20022006, Hacia un estado comunitario. Disponible en: https://www.dnp.gov.co/ Plan-Nacional-de-Desarrollo/Paginas/Planes-de-Desarrollo-anteriores.aspx

Gobierno de Álvaro Uribe-Vélez, segundo período, Plan Nacional de Desarrollo 2006 2010, Estado comunitario. Disponible en: https://www.dnp.gov.co/Plan-Nacionalde-Desarrollo/Paginas/Planes-de-Desarrollo-anteriores.aspx

Gobierno de Andrés Pastrana-Arango, Plan Nacional de Desarrollo 1998-2002, Cambios para construir la paz. Disponible en: https://www.dnp.gov.co/Plan-Nacional-deDesarrollo/Paginas/Planes-de-Desarrollo-anteriores.aspx

Gobierno de César Gaviria-Trujillo, Plan Nacional de Desarrollo 1990-1994, La revolución pacífica. Disponible en: https://www.dnp.gov.co/Plan-Nacional-deDesarrollo/Paginas/Planes-de-Desarrollo-anteriores.aspx

Gobierno de Ernesto Samper-Pizano, Plan Nacional de Desarrollo 1994-1998, El salto social. Disponible en: https://www.dnp.gov.co/Plan-Nacional-de-Desarrollo/ Paginas/Planes-de-Desarrollo-anteriores.aspx

Gobierno de Juan Manuel Santos, primer período, Plan Nacional de Desarrollo 20102014: Prosperidad para todos. Disponible en: https://www.dnp.gov.co/PlanNacional-de-Desarrollo/PND-2010-2014/Paginas/Plan-Nacional-De-2010-2014. aspx

Gobierno de Juan Manuel Santos, segundo período, Plan Nacional de Desarrollo 20142018: Todos por un nuevo país. Disponible en: https://www.dnp.gov.co/Paginas/ Conozca-el-Plan-Nacional-de-Desarrollo-2014-2018-.aspx

\section{Documentos, informes, reportes}

Consejo de Política Económica y Social, Conpes, Documento Conpes 2750, Política nacional ambiental, Salto social hacia el desarrollo humano sostenible (Ministerio de Ambiente, Departamento Nacional de Planeación, DNP, Unidad de Política Ambiental, UPA, Bogotá, 21 de diciembre de 1994). Disponible en: https:// colaboracion.dnp.gov.co/CDT/CONPES/Econ $\% \mathrm{C} 3 \%$ B3micos/2750.pdf

Foro Nacional Ambiental, FNA, Las licencias ambientales y su proceso de reglamentación en Colombia (Análisis 01, Foro Nacional Ambiental, Bogotá, 2011). Disponible en: http://www.foronacionalambiental.org.co/wp-content/uploads/2011/11/ AnalisisFNA-001.pdf

Ministerio de Medio Ambiente, Política nacional de producción más limpia (Bogotá, 1997). Disponible en: https://www.minambiente.gov.co/images/ BosquesBiodiversidadyServiciosEcosistemicos/pdf/Normativa/Politicas/ polit_produccion_mas_limpia.pdf 